\title{
Domestic Debris Management and Community Health Security in Ibadan, Nigeria \\ DOI: 10.36108/NJSA/3102/11(0270)
}

\author{
Blessing Nonye Onyima \\ Department of Sociology and Anthropology \\ Nnamdi Azikiwe University \\ Awka, Anambra State, Nigeria \\ nonyelin2003@yahoo.com
}

\begin{abstract}
Differential domestic debris management has implications on health security in cities. Within the last four decades, Ibadan has retained the identity of a dirt city. The Ogunpa water channel constructed after the devastating flood of the 1980s remains attractive for domestic wastes disposal. This multi-site comparative ethnographic study employed qualitative anthropological methods as data collection tools, using rational choice model as an explanatory framework to unravel covert factors responsible for the protracted dirtiness identity. Ethnographic data reflect disparity in private and public waste management efforts across high, middle and low income residential areas. Persistent poor wastes management due to rational choices, poor urban policy and lack of proper public environmental health education, resulting in unwholesome health problems in Ibadan, render the attainment of community health security a mirage. As such, the study recommends among other things, a more balanced waste management execution policy across board in cities.
\end{abstract}

Keywords: rational choice, domestic debris, health risk, health inequality, community health security

\section{Introduction}

Unequal management of domestic debris in cities, based on the socio-economic characteristics of residential areas, persists in most developing countries and this has great implication on the actualization of community health security. This is linked to rational choices made by government waste management officers, private wastes evacuators and individuals in managing domestic debris or wastes. Ritzer (2012: 445) posited that in making rational choices, "persons act purposively toward a goal, but that goal and actions are shaped by values and preferences." This paper associates the intractable dirty nature and poor management of wastes in cities to the preference by city waste managers to differentially manage domestic debris across existing strata of residential areas. Thus, Alaszewski \& Coxon (2008: 414) assert that:

Contemporary society is a 'risk society' in which individuals have become responsible for managing an increasing range of risks, many of which can be identified by specialist expertise, and are often generated by global processes which have the capacity to destroy both individuals and communities. 
On the contrary, stakeholders who design policy to manage wastes differentially or unequally across residential areas fail to take cognizance of the fact that when community health security is threatened by potential health risks and disasters such as flood, disease outbreak and epidemics, the impact is hardly restricted to particular residential areas. Ibadan typically exemplifies a city where rational choices play out in differential domestic debris management even to the extent of tinting its identity. This 'dirtiness identity' has often attracted the attention of scholars, government, journalists and poets (Onyima, 2010). Hence, in 1975, John Pepper Clark, in his poetic imagination of Ibadan city, touched on a sensitive aspect of Ibadan identity in his poem titled "Ibadan."

\section{Ibadan \\ running splash of rust \\ and gold-flung and scattered \\ among seven hills like broken \\ China in the sun (Clark, 1975: 142)}

Ibadan - rusty, flung and scattered... since 1975 - seems unchanged positively except that the "rusty, dusty and filthy nature of Ibadan" (Soyinka, 1994: 75) continues to persist in such a way that makes Ibadan be synonymous with a filthy space. Even in the 2000 s, a number of references are still made to the polluted space due to improper management of domestic wastes in Ibadan city (Asakitipi, 2004; Ajala, 2005). While the question of identity is difficult to ignore, the health imperatives of the Ibadan 'filthy identity', and why it persists, can best be contextualized in the nature and prevalence of the production of domestic debris and its management in Ibadan city.

Historically, Ibadan was said to be initially slow to embrace western education (Ajala, 2008); this partly seems to be a factor for poor sanitation, and for the dirty and unplanned nature of Ibadan space. Over the years, the monster - 'domestic debris'- continues to give Ibadan derogatory label among people of different persuasions. Hence, Lawuyi (2004) presents a graphic picture, which typically captures the characteristic feature of the sanitation situation in Nigerian cities like Ibadan. In his narration of power, identity and waste control on public space, Lawuyi (2004: 40-41) maintains that "there is no public refuse depot and definitely no refuse bins in many houses." In this context, domestic debris is deposited on undeveloped properties, or thrown into the streams.

For instance, a pilot survey conducted in preparation for this study found, in Ajibode community of Ibadan that most waste materials are left on or around road embankments, in dug up pits or at edges of streams. This compounds the chaos in community health security, as filth gathers around buildings (both public and private) and increases human exposure to risk. In terms of waste management, the environmental condition in Ibadan is so worrisome that Tejuosho (2004: 5) observes that the careless disposal of domestic debris constitutes environmental, social, psychological and emotional 
disturbances to its residents, which in turn translates into a series of risks in the city. This places Ibadan on a status of disease vulnerability, which according to Alwang, Siegel \& Jogenson (2001); Asakitikpi (2004), and Ajala (2005) predisposes the inhabitants to a number of health risks.

The risk becomes a big concern as Ibadan population continues to increase 'abnormally', within the interface of choice in keeping a peculiar identity and attachment to traditional settlement patterns and insensitivity to health education. This also explains why parts of Ibadan metropolis, continue to exist on scattered and clustered residential patterns with endemic environmental degradation caused by domestic debris. The lingering problem of poor wastes management continues due to the self-destructive choice of corruption and bribery on the part of the environmental health enforcement officers. This has defiled several efforts to sanitize the city and has given rise to public concern, as well as generating both academic and media discourses. This concern also spurred the Oyo State Commissioner for Environment to visit Calabar (reputed to be one of the cleanest cities in Nigeria) in December 2009 in a bid to adopting a better waste management policy for Ibadan city (Radio Nigeria Premier FM, 2009). Yet the problem of waste or debris management in Ibadan seems intractable. The protracted problem has therefore, instigated the need for further investigation:

- Why is the 'monster' of domestic debris difficult to manage?

- In what ways does domestic debris constitute health risks?

- What roles do social structures play in the relationship between space, domestic debris management and health in Ibadan?

- And what are the possible ways of controlling the menace?

\begin{abstract}
A Review
Poor waste management: $A$ resilient culture in Ibadan

The problem of domestic debris has a long history in Ibadan. Omoleke (2004) asserts that the issue of solid wastes dumping in Ibadan dated back to early 1960s when Ibadan City Council was responsible for the maintenance of Ibadan city. Omoleke (2004: 267) further describes Ibadan residents as having "uncivil culture of indiscriminate waste littering." The city was characterized by people's inability to maintain a sanitarily clean environment, and reluctance of people to cooperate with the authorities by choosing to dispose solid waste in illegal dumps rather than using the means provided by the government. The 'dirt culture' associated with residents of Ibadan city has become a collective public concern; it appears there is seemingly no solution to the quest to curb and arrest the menace of domestic debris in the city. Certain scholars have given up on Ibadan, and have even made categorical statements to the effect that "this ugly situation persisted for the past decades, since independence and will continue to be so in Ibadan" (Omoleke, 2004: 267). Thus, improper management of domestic debris has become a resilient culture in Ibadan which
\end{abstract}


may have its roots in rationalization by wastes managers, residents' attitudes and thought processes and may require a massive reorientation of the people.

From the foregoing, managing domestic debris effectively in Ibadan is a herculean task. But Ibadan is not an isolated case among other Nigerian cities. Indeed this is confirmed by Sridhar, Olaseha, Adeoye, Tajudeen \& Ogunwolere (2008) in their study on sustainable waste management in Nigeria. To them;

Solid waste management is a serious problem in Nigerian cities. The communities with poor knowledge and attitude resort to dumping the wastes into any available space such as drains, streams or on the road side. Many solutions tried in the past such as private sector collection, sending to land fill sites, incineration and waste to energy conversion by successive state and federal governments have failed due to lack of sustainability (Sridhar et al., 2008: 103-112).

However, what obtains currently in Oyo State reflects some sort of rational choice or policy by the government to concentrate on removal of public wastes, while domestic garbage is left to the whims and caprices of profit motivated private refuse contractors.

\section{Disparity in domestic debris collection and management in residential areas of cities}

The issue of social inequality has always been with man, hence the concept of social stratification in anthropological studies. According to Taylor \& Allen (2006: 343), "in many low to medium income parts of the world, uncontrolled open dumps are common, and all wastes tend to be dumped together, regardless of its origins or its hazardous nature." Taylor \& Allen (2006), citing OECD (1997), also observed that "the rate at which waste is generated corresponds roughly with levels of income. In high income counties of Europe and North America, 500 and $750 \mathrm{~kg}$ of solid wastes are produced per person per year', In contrast, urban populations in most low income countries, for example, in Nigeria and Cote d'Ivoire, generate between 100 and $200 \mathrm{~kg}$ of solid waste per person per year (Onibokun \& Kumuyi, 1999).

Despite this lower rate, rapid urbanization in low income developing countries has left little space for disposal of the increasing waste material being generated (Sangodoyin, 1993). Thus, the disparity in domestic debris generated in developed and developing worlds may have reversed in recent years with the waste generated in the developing world geometrically exceeding that of the developed world due to rational choices, poor management policy and implementation. Thus, Allen \& Taylor (2006: 345) observe that "the composition and volume of disposed wastes vary nationally and regionally in relation to the local human activities, and the quantity and type of products that communities consume." Ibadan wears the appearance of a city where massive wastes are generated only because the disposal of waste has been inefficient, 
not because it generated more wastes than other cities relative to their population size.

\section{Rational Choice in Ibadan Waste Identity}

The Rational Choice Model (RCM), also known as 'Cognitive Rational Actor Model, was propounded by Gary S. Becker a rationalist economist. The main thrust of the model is that "the mind was thought to have inherent organizing powers" within which a particular position is constructed in the context of a perceived world. This position is related to choices of ideas through cognition and values; such choices are often made in lucid (clear) term based on the notion of 'structures of thought' (McGuire, 2000). This suggests that the structure of the human mind works to influence human behaviour. The construction of Ibadan as filthy, rusty and the disparity in waste management of cities, as well as the people's perception of health risks, can be explained through the rational choice model.

Evolving from the above background in the rational choice perspective, the basic idea is that patterns of behaviour in societies reflect the choices made by individuals as they try to maximize their benefits and minimize their costs. This suggests that most city residents/individuals and government waste management agencies tend to make presumed rational choices and sometimes do certain things that are anti-norm and then rationalize to authenticate their actions as good. Thus, in the opinion of Henwood et al. (2008), rational actors' perspectives tend to view individuals as making (objectively) rational choices to minimize risks.

To Henwood et al. (2008: 423), perceptions of the "riskiness" of a situation depend on the interactions among context and culture, individual biography, people's everyday lives, and a variety of available frames (risk perception), several of which may be competing at any time. Underlying the above is a subjective interpretation of actions as risks. While in many occasions, risks bearers engage in rational choice to ignore their risky action, those with expert knowledge of controlling risks impose their acclaimed superior knowledge to locate risky actions. Within this context, Henwood et. al. (2008) are correct in their observation that most people do not interpret risk as an objective category, but live with risk using their culture, available symbols, and their sense of aesthetics to make judgments and to rationalize risky action as unrisky. Thus, residents of Ibadan see nothing wrong about their supposedly 'rational' means of disposing refuse at the most convenient space. This confirms Lisa's (2009) assertion that cognitive rational choice theory assumes that humans are logical beings that make the choices which make the most sense to them.

\section{Methodology}

This study drew on a qualitative ethnography sourced from a multi-site field study. It specifically employed participant observation, key informant and indepth interviews as methods of data collection. The study areas were 
purposively selected considering the levels of stratification in Ibadan, which is largely reflected in the Ibadan residential patterns. For the purpose of this study, Ibadan was stratified into three residential patterns, namely:

- The Low Income Residential Areas (LIRAs), mostly the traditional settlements in Ibadan, including: Bere, Oje, Inalende, Itamerin, Opoyiosa, Agbeni, Ogunpa, Ayeye, Agbowo, Labo, Gege-Olorun, and Odo-Ona among others.

- The Medium Income Residential Areas (MIRAs) include Ajibode, Orogun, Samonda, Eleyele and Sango among others.

- The High Income Residential Areas (HIRAs), including New Bodija estate, Oluyole-Extension, Alalubosa, Akobo, and University of Ibadan staff quarters among others.

The city was so divided, to provide representative data to cover all classes of residents in the city. Each site was investigated to ascertain different risky situations common in the area as a result of domestic debris. Through the lucky-dip simple random technique, the following sites were selected for the study: New Bodija (HIRA), Ajibode (MIRA) and Inalende (LIRA). Staff of the Oyo State Ministry of Environment and Water Resources and the Oyo State Solid Waste Management Authority in charge of wastes and environmental management, considered relevant to the study were also purposively selected and interviewed. The three study sites belong to different LGAs, and thus provided the opportunity to compare the strategies employed in waste management by their different local authorities. From each of the sites, 30 households/respondents were selected based on gender, educational level, religious affiliation and income levels, giving a total of 90 respondents in all. The study generated purely qualitative data, and manual content analysis was used to sort and analyze the data thematically based on the research objectives.

\section{Research Findings}

The study found that there is a marked disparity in the management of domestic wastes in the three selected strata of residential areas in Ibadan city. The study revealed that domestic debris produced by people living in high income residential areas are properly evacuated and disposed of, due, mainly to the fact that they can afford to pay private waste evacuators/contractors. On the other hand, domestic wastes produced by those living in the middle and low income residential areas are partially disposed of, or not disposed at all, a function of their inability to pay private waste evacuators. The government or public wastes evacuators rarely get to these areas because of inhibiting factors such as availability of few ultra-high tech refuse compactor vehicles, narrow roads to allow easy passage of the ultra-high tech refuse compactors, inadequacy of environmental sanitation officers, among others. More specific 
findings are presented below with respect to different residential areas of the city covered by the study.

\section{Low income residential area: Inalende}

This is one of the core indigenous areas in Ibadan city situated at Ibadan NorthWest Local Government Area. Domestic debris was seen littered all around the environment, with no proper channel for sewage. Black dirty water flowed on bare ground without proper channels. In some of the compounds visited, there were no toilets; basins and nylons were lined up beside the houses for storage of human fecal waste. Respondents gave several rational reasons for this problem such as: government does not provide dumping grounds; there is no space to construct new toilets once the old got filled up; and the people are poor and as such cannot afford to pay private wastes evacuators. There was also the issue of gender-based division of labour as a culture among the people; it is believed that it is the duty of women/children to clean and dispose wastes, thus leaving able-bodied men off the challenging task of waste management.

A respondent in New Bodija estate (interviewed on 19/6/2010) rationalized on the reasons low income residential areas (LIRAs) are dirty:

It is only the local areas that are dirty because private collectors cannot go there as there are no planned streets to enable the free passage of vehicles to evacuate their wastes and drain their sewages, and that is why those LIRAs are prone to more health risks like dysentery, cholera, malaria. They stand the risks of an outbreak of epidemics in the nearest future if a drastic resolution is not taken for the core areas of Ibadan city.

The study, however, discovered a private refuse evacuator known as Agala in this area who collects just 20 naira from residents to dispose their domestic wastes no matter the volume. But most residents say they cannot afford 20naira; rather they prefer to dump wastes at night (in order not to be caught by the police) at the Ogunpa water channel constructed by government after the infamous flood (omiyale) which occurred in the 1980s.

\section{Middle income residential area: Ajibode}

This ethnographic study found that the Ajibode community situated at Akinyele LGA of Oyo state is structurally divided into two parts. The Aho estate is occupied by middle class civil servants, lecturers and other educated elites, and is conspicuously in contrast with the main Ajibode area resided by indigenes, mostly farmers, traders, artisans, etc. Mere observation reveals that the Aho area of Ajibode is well planned, with new buildings although mostly uncompleted, being a new estate. The compounds are fenced with gates, well planned streets, and the environment very clean without dirt littered all around. In contrast, in the main indigenous area of Ajibode, there are no demarcation in between houses, no house numbering, the buildings are mostly dilapidated and without toilets and bathroom. Refuse evacuators do not come to this area 
because the major entrance/road to the community is always flooded, so the residents burn or dispose wastes into the stream that divides the community into two parts.

\section{High income residential area: New Bodija Estate}

The New Bodija estate, located in Ibadan-North LGA, is a serene, cool, neat, environment with class conscious residents. The estate is divided into zones, and residents are also conscious of health security and environmental sanitation. According to a respondent (interviewed on 26/6/2010):

In this estate, there are landlords and tenants associations in each zone. On every last Saturday of each month we hold meetings on welfare and security of the residents and cleanliness of the environment. It often starts at 7 am and ends at 9am; all gates are shut, and no one moves out, any defaulter or stubborn individual is arrested by the Police. The agreement in this estate is that if one cannot clean up, or cut grasses within and around his/her compound, then one must hire and pay labourers to do so, as dirtiness in the estate is not encouraged in any form.

The findings of the study based on a thematic analysis of the research objectives are presented below.

Why the 'monster' of domestic debris is difficult to manage

The failure to manage waste properly in Ibadan hinges on how rationalization plays out among stakeholders, including residents, government, and waste managers. The above differences in the management of domestic wastes reflect disparity in the degrees of rational choices made by government and residents in the three residential areas of Ibadan city studied. Some choose to maximize the short-run benefits at the expense of a long-run advantage. This implies that residents at LIRA choose to live with health risks, spend money on drugs at hospitals and patent medicine stores instead of choosing to properly dispose domestic wastes. When caught disposing wastes improperly they choose to give bribe to corrupt wastes management officers which is at their own detriment in the long-run.

On the part of government, the Oyo State Wastes Management Authority makes rational choices in so many ways, for instance, by employing temporary none professional environmental staff as direct evacuators which entrenches lack of commitment to duty (the existing 49 enforcement agents for the whole of Ibadan is grossly inadequate), and by involving profit-motivated private refuse evacuators/contractors who only choose to dispose domestic wastes from the high income residential areas, leaving inhabitants of the low income residential areas to live with health risks emanating from improperly disposed wastes. The above rational choices by government paint a picture of a disproportionate wastes management policy, which has in the long-run resulted to health insecurity in Ibadan city. Onyima (2010: 105) attributes this to the 
"pressure of competing needs, as the minds of residents/governments become the seat of rationalization, the table of decision and platform for choice making. The mind tries to maximize its profit and minimize cost/loss and then swifts into action." The resultant effects of these actions are intractable manifest and latent health risks/insecurity.

\section{Ways domestic debris constitute a health risk in Ibadan city}

Health risks are potential impact of a chemical, biological, physical or social agent on a specified human population under a specific set of conditions and for a certain time frame, (en Health 2002: xviii). Epidemiological studies in medical anthropology focus on patterns of diseases in a population and the factors that influence these diseases. Risk is a measure of potential harmful effects (hazards) to health from exposure to a substance, process or product and the probability of harm occurring as a result of exposure, (Stephen, Hicks, Craig, \& Shortreed, 2000). The poorly managed domestic debris in Ibadan pose great health risks to residents and this study reveals that these potential health risks are in three forms.

First are biological risks, such as diseases mostly carried/transferred by vectors such as flies, fleas, rats, lice, bedbug and air-borne micro-organisms that easily breed in decaying domestic debris. These potential biological health risks vary across the different residential areas in Ibadan city. The low income areas are exposed to more of these diseases as their domestic wastes are hardly collected. Daily, they live with lethal decomposing and stinking human excreta, decomposing bodies of dead animals, dark smelling stagnant mosquito infested sewage/water meandering in shallow gutters and narrow pathways within the neighbourhoods. The common ailments are dysentery, cholera (igbegburu), malaria, tuberculosis, measles, and chicken pox, hook worm infestation, typhoid, fever, catarrh and cough, etc. due to improper dumping. These also featured at the indigenous area of Ajibode community directly opposite the Aho Estate in Ajibode occupied by middle income earners (MIRAs).

Secondly, the study identified socioeconomic risks as one of the repercussions of poor wastes management in Ibadan. For instance, wastes dumped into Ajibode stream blocks drains and roads, hence the roads are often flooded. Those who own vehicles in Ajibode are not able to bring them into the community; resident resorted to using University of Ibadan main gate and then pass through a wooden bridge constructed along the boundary between Ajibode and the University. These vehicles stand the risk of being stolen when parked at the boundary of the Botanical Garden, University of Ibadan and Ajibode community, as reported by a resident whose car was stolen where it was parked at that location.

The third potential health risk is a natural health hazard. Ibadan stands the risk of experiencing a future flood inundation of most of its core residential areas. This prediction was fulfilled on 26 August 2011 when flood ravaged Ibadan, which led to the establishment of temporary refuge camps to alleviate 
the suffering of displaced people. Occasionally, flood has caused havoc in different areas of the city due to blockage of drainages with domestic debris. Ethnographic data from Ajibode show that one main problem of residents is the flooding of their major road all year round. The location of the community in a sloppy terrain makes it pliable to flood from Orogun and other neighbouring communities, all heading into the Ajibode River.

Flooding pose seasonal health risks in Ibadan; they are not always there but surface at the peak of rainy seasons or dry seasons depending on the nature/type of diseases. Decomposing domestic debris often emit bad odour into the air, thereby causing social and psychological discomfort to residents in the city. Thus, Mohit (2000) observed that indiscriminate littering on roads, lanes, and by-lanes leads to emission of bad smells from drains clogged with wastes, and as a result, the living environment is deteriorated. Ogbonna, Ekweozor \& Igwe (2002) observed that the presence of wastes and unsanitary wastes' dumps degenerate and destroy the aesthetic value of the environment.

\section{Social Structures in the Relationship among Space, Domestic Debris Management and Health in Ibadan}

Several implicit and covert social structures identified in this study play important roles in the protracted poor domestic waste management in Ibadan, thereby preventing the attainment of community health security. These include:

\section{Inaccessibility and Unavailability of Health Facilities}

Despite the numerous potential health risks discussed above, which residents are exposed to daily, there are little or no health management facilities to serve as a corresponding antidote, especially in most low income residential areas in Ibadan city. The ancient city of Ibadan is privileged to have the University College Hospital (UCH), the nation's first teaching hospital, Oluyole hospital, and many other government and private hospitals, pharmacy shops and health centers. Yet most low income residents only have access to chemist shops where medicines, injections, and treatments are administered by private health care providers and their apprentices. Inaccessibility to $\mathrm{UCH}$ was explained by poverty or lack of money to pay for hospital bills as well as the bureaucratic setup at $\mathrm{UCH}$, which invariably leads to long delays before one can be attended to by nurses and doctors, no matter how critical the health condition may be. Most respondents called on the government and management of UCH to reconsider their policies and procedures, and become patient-friendly.

There is also little presence of primary health care (PHC) facilities in most communities in Ibadan, and where they are found most are not functioning. Those functioning face insufficient staff, drugs, and other necessary technology and facilities needed to perform to optimum. The 1978 Alma-Ata declaration on primary health care of the World Health Organization (WHO) emphasized the need for accessibility, affordability, and availability of primary health care service at the grassroots level. The unavailability of affordable and adequate health care through proper health management makes most residents to resort 
to taking agbo - a traditionally concocted herbal medicine for treating malaria, typhoid and dysentery. According to Kottak, "all societies have health-care systems which consist of beliefs, customs, specialists and techniques aimed at ensuring health and preventing, diagnosing and curing illness" (Kottak 2004: 44). In Ibadan, agbo herbal concoction is often used by residents as preventive, therapeutic and also curative purposes. This implies that alternative medicine plays a complementary role to other health-care systems available to Ibadan residents and also doubles as a medium of health management in the city. The use of agbo and other traditional herbal medicines in prevention and treatment of some of the above mentioned diseases, caused by improper management of domestic/household wastes is propagated and perpetuated by the folk and popular sectors of the health care/management system.

\section{Inefficient Monitoring of Sanitation Exercises}

Poor waste management also persists in Ibadan because of inefficient monitoring of the monthly sanitation exercise in the city due to insignificant number of sanitation officers. A respondent at the Oyo State Solid Waste Management Authority put it this way:

We have a meager number of officers and they have already reached the peak of their careers because they are about to retire. They are not expected not to go out for enforcement again; however they but give advice to younger staff who are new on the job (personal communication, 23/06/2010).

This implies that there is a need to employ able-bodied and younger men as the present crop of waste management staff are aged. Finally, monitoring and evaluation of the wastes management activities in the city is also central to proper implementation. There is also need to emphasize community participation by upholding the Alma-Ata Declaration of 1978 and the incorporation of teachings on personal hygiene and sanitation into our educational curriculum and in religious institutions, to ensure a holistic solution to the problem of wastes in Ibadan city.

Concentration on Collecting Public Wastes Rather Than Domestic Wastes

The wastes management authority concentrates on collecting and disposing public wastes, while commercial, industrial, and domestic wastes are contracted to Private Refuse Contractors (PRC). Public wastes are wastes dumped in public places like road sides, streets, believed to come from residential areas. By this arrangement, the irony is that PRCs focus on collecting domestic debris in GRAs and estates as they are profit-driven, and ignore the LIRAs because they cannot afford to pay for refuse disposal. They are left with no other option than to live with health risks give the infrequency of wastes collection and disposal in LIRAs. The Oyo State Waste Management Authority (OYSSWMA) needs to review this problem and ensure that the 
authority/government collects domestic wastes only in LIRAs while the GRAs and estates maybe contracted to private enterprises.

\section{Gender-based waste management culture}

This is another factor responsible for improper wastes management in Ibadan. This ethnographic study reveals that the division of labour based on gender consciousness, often specified by culture, makes able bodied men who are supposed to help out in cleaning up the environment usually abandon this task to women and children alone. People living in the LIRAs who hold tenaciously to the cultural specifications that domestic debris disposal and management are the responsibility of women need to be re-educated by governments and civil society organizations. Since this was not the case in the HIRAs, where men often use their cars to dispose of domestic debris thereby relieving their wives and children of the stress and burden such tasks, it is not inherently cultural that women should be the ones to dispose of wastes.

\section{Cost Consideration and Poor Funding of Wastes Management}

Monetary considerations make certain residential areas in Ibadan City vulnerable to potential health risks from infectious domestic debris. This ethnographic study discovered that most LIRAs are not willing to pay for wastes disposal as they see wastes collection as the responsibility of the government. This contradicts the finding by Onibokun \& Kumuyi (1999: 101-172), who found in their survey that "people in Ibadan are willing to pay if the services are improved." This may be true only in the high income residential areas (HIRAs), and this assertion underscores the importance of a comparative (qualitative) study relative to generalizations from a (quantitative) study which might not reflect the situation in particular segments of the population.

Even the willingness to pay for wastes disposal in the HIRAs remains contestable. The planning, research and statistic officer (PRS) at OYSSWMA averred: "You would not be surprised that the estates and GRAs still request for bins and other wastes receptacles from the authority" (interviewed 23/06/2010). She further stressed that the available receptacles cannot go round, and that the GRAs should therefore help the government to provide such, so that the available ones could be placed in the low income/core areas of the city. Onibokun and Kumuyi (1999: 101-172), however, confirmed that "most segments of the population believe that they should not bear the responsibility whatsoever for wastes collection and disposal" as they hold the erroneous belief that wastes disposal is solely the responsibility of government.

\section{Insufficient staffing and unequal treatment of wastes management staff}

Onibukun (1997) cited by Onibokun and Kumuyi (1999) identified lack of professional staff as a factor making the wastes management authorities seem like purposeless bodies and a drain on the government. Why should a sanitary officer prefer to collect bribe rather than strictly enforcing the law on defaulters? Are these health officers not well remunerated? Although, 
Onibukun and Kumuyi had already observed that poor conditions of service exacerbated the situation, as there was no harmonized remuneration for federal, state and local government staff. The waste management section attracts the least pay, this makes them feel inferior and the situation considerably lowers morale and promotes slothfulness.

The study revealed disparities in the remunerations of wastes management staff; those who do direct disposal, and who are therefore continuously exposed to inhaling bad odour from these wastes receive the lowest pay/salary. That rational choice by the government to pay administrative staff higher than direct evacuators is arguably questionable. On the other hand, a key informant at the Oyo State Solid Waste Management Authority emphasized on the numerical strength of direct environmental personnel in Ibadan; lamenting on the inadequacy of the number such workers, he contrasted the total number of environmental officers with the WHO standard stipulates that there should be one environmental officer to every 1,000 people. This implies that the city of Ibadan is grossly understaffed with respect to environmental cleaning, and for better results the government should increase the work force in the east management department.

\section{Priority on security rather than sanitation}

The study also reveals that priority is given to security matters relative to sanitation issues in Ibadan City. This implies that Oyo State government rationally chooses to expend its funds/resources on security matters rather than on sanitation and health security. It is pertinent to therefore rationalize and question, if good community health security could be sacrificed on the altar of social security. Clearly, the two are important, but one should be addresses at the expense of another. Oyo State government should therefore appropriately and judiciously allocated its resources in such a way as to ensure that no aspect of the people's life and wellbeing is neglected.

\section{Conclusion}

In sum, the paper has revealed that there is a point at which rational choices become irrational choices and that there is a link between rational choices, domestic debris management and health security. This is manifested in the loss of value and corruption on the part of defaulting individuals and unprofessional wastes management officers who collect bribe from defaulters thereby stalling government efforts to properly manage wastes in cities. Put differently, choices, decisions and policies are often rational in the short-run but sometimes irrational in the long run. Hence, Embers (1973: 518) stressed that "planned change, decisions and policies have beneficial consequences in the short-run, but a great deal of thought and investigation has to be given to their effects in the long run." Therefore, when stakeholders: governments and individuals make logical policies/decisions, they must take into cognizance the short-run and long-run rationality of their rational choices and decisions. 
Also the study argued that the differential management of domestic debris based on the socio-economic characteristics of residential areas and contracting of waste disposal to private waste evacuators has engendered the protracted dirty nature of Ibadan city as well as render the disadvantaged low income residential areas more vulnerable to health risks. The study revealed covert factors that influenced competing needs and choices made by individuals, government and all stakeholders involved in wastes and health management who resort to rationalization to authenticate their actions, hence the use of the rational choice model as an explanatory framework.

Finally, it highlighted that the monitoring and evaluation of wastes management activities is central to effective and efficient implementation. The role of gendered cultural specifications tenaciously propagated in low income residential areas that wastes disposal is the duty of women and children, which negatively contributes to poor wastes management was also highlighted. There is also a need to embrace community participation in wastes management issues by upholding the Alma-Ata Declaration of 1978 and the incorporation of the teachings on personal hygiene and sanitation into our educational curriculum and religious institutions. It is also imperative to encourage private efforts in wastes management as government cannot do it alone. All these would ensure a holistic solution to the problem of waste management and attainment of community health security in Ibadan city.

\section{References}

Ajala, A.S. 2005. Space culture and health attitudes: A threat to child survival in Ibadan city, Nigeria. Journal of Environment and Culture. 2(2):106-117.

Alaszewski, A. \& Coxon, K. 2008. The everyday experiences of living with risk and uncertainty. Journal of Health, Risk and Society. 10(5):413-420.

Alwang, J.; P. Siegel \& S. Jogenson. 2001. Vulnerability: A view from different disciplines and profitability of agricultural investments. Economic Journal. January. 103:56-78.

Asakitikpi, E.A. 2004. Risk factors influencing the incidence of childhood diarrhea in Ibadan Metropolis, Oyo state Nigeria. A PhD Thesis in Department of Sociology, University of Ibadan.

enHEALTH. 2002. Environmental health risk assessment. Guidelines for assessing human health risks from environmental hazards. Commonwealth of Australia.www. health.gov/au/pubhlth/strateg/enhlth/risk/.

Henwood, K.; N. Pidgeon; Sarre, S.; Simmons, P. \& Smith, N. 2008. Risk, framing and everyday life: Epistemological and methodological reflection from three social cultural projects. Journal of Health, Risk and Society. 10(5):421-438.

Kottak, C.P. 2004. Anthropology: The Exploration of Human Diversity. New York: McGraw-hill companies Inc. 
Lawuyi, O.B. 2004. Space and Sanitation: Identity Power and the Management of Refuse in Osogbo. Nigeria. Journal of environment and culture. 1(1):38-50.

Lisa, F. 2009. Cognitive Theory. http://phobiasabout com/com/od/glossary/g/cognitivethedef.htm. Retrieved 2/6/2010.

Mc Guire, J. 2000. Cognitive Behavioural Approaches: An introduction to theory and research. Liverpool, UK, Department of Clinical Psychology, University of Liverpool.

Mohit, M.A. 2000. Community Participation in Solid Wastes Management of Dakar City - A case of Kalabagan Area. A paper presented at the CAP conference, Belfast.

Ogbonna, D.N.; Ekweozor, I.K. \& Igwe, F.U. 2002. Wastes management: A tool for environmental protection in Nigeria. AMBIO: A Journal of the Human Environment. http://ambio.allenpress.com/periserv/?request=getdocur. Retrieved 14/7/2010. 31(1):55-57.

Omoleke, I.I. 2004. Management of Environmental Pollution in Ibadan, an African City: The Challenges of Health Hazard Facing Government and the People. Journal of Human Ecology. 15(4):265-275.

Onibokun, A. \& Kumuyi, A. 1999. Ibadan Nigeria. Onibokun A.G. (ed.). Managing the Monster: Urban waste and governance in Africa. Ottawa, IDRC. 101-172.

Onyima, B.N. 2010. Living with risks: Domestic debris and health management in Ibadan Nigeria. An unpublished Master's thesis at the Department of Archaeology and Anthropology. University of Ibadan, Nigeria.

Ritzer, G. 2012. Sociological Theory. New York: MacGraw-Hill international. $8^{\text {th }}$ Edition.

Sangodoyin, A.Y. 1993. Considerations on Contamination of Groundwater by Waste Disposal System in Nigeria. Journal of Environment Technology. (14):957-964.

Soyinka, W. 1994. Ibadan: The Penkelemes Years - A memoir 1946-1965. Ibadan: Spectrum Books, Ibadan.

Soyinka, W. 1975. Poems of Black Africa. (ed.). Heinemann Educational Books Ltd, Jordan Hill Oxford.

Sridhar, M.K.C.; Olaseha, I.O.; Adeoye, G.O.; Tajudeen, T. \& Ogunwolere, B.C. 2008. Sustainable waste management through integrated waste recycling. International Journal of Environmental, Cultural, Economic and Social Sustainability. 3(3):103-112.

Stephen, M.; Hicks, J.; Craig, L. \& Shortreed, J. 2000. Environmental health risk management. A primer for Canadians Graphic Services University of waterloo, Canada.

Taylor, R. and A. Allen. 2006. Waste disposal and landfill: Potential hazards and information needs. Schmoll, O.; Howard, G.; Chilton, J. \& Chorus, I. (eds.). World Health Organization, protecting groundwater for health: Managing the quality of drinking water sources. London: IWA publishing. 
116 The Nigerian Journal of Sociology and Anthropology Vol. 11

Tejuosho, O.O. 2004. Assessment of Generation and Management of Hazardous Household Wastes in Selected Communities in Ibadan. An M.P.H. Dissertation at Department of Epidemiology, Medical statistics and Environmental health, University of Ibadan, Nigeria. 